Revista Iberoamericana, Vol. LXXX, Núm. 247, Abril-Junio 2014, 327-349

\title{
DERROTA, MELANCOLÍA Y DESARME EN LA LITERATURA LATINOAMERICANA DE LAS ÚLTIMAS DÉCADAS
}

\author{
POR \\ Ana María Amar SÁnchez \\ Universidad de California-Irvine \\ TEREsa BAsile \\ Universidad Nacional de La Plata
}

\section{Preliminares}

Esta antología procura recolectar y poner en diálogo algunas propuestas que, desde la literatura y desde los debates intelectuales, exploran ciertos nudos significativos de las derrotas de la izquierda revolucionaria; revisan las macronarrativas y sus aristas utópicas; indagan las nuevas políticas del "derrotado"; reflexionan en torno al duelo y la melancolía como modos de elaborar las pérdidas; interrogan las nuevas condiciones de la literatura y el lugar del intelectual posrevolucionario en la escena latinoamericana; interpelan los vínculos entre la escritura y lo indecible, y rastrean los imaginarios literarios que la derrota va desgranando. Todo lo cual significa considerar un corte en la historia y la cultura latinoamericanas que se da en el trayecto final del siglo xx.

Ciertas fechas y acontecimientos de la historia resultan emblemáticas en esta trama signada por el derrumbe de la izquierda armada, y algunos mojones suelen tener valor como hecho histórico y a la vez como símbolo, aunque las temporalidades en varias ocasiones se cruzan, se corren y desajustan. Muchos han señalado como día clave de la "derrota” el 11 de septiembre de 1973, día del golpe de Estado contra el gobierno de Salvador Allende, cuya caída y muerte constituyeron "un trauma dentro de la historia del fracaso de las utopías en Latinoamérica, en el siglo xx” (Spiller 145). Para Idelber Avelar-siguiendo a John Beverley- esta fecha cobra un valor importante para el campo literario como momento inicial del ocaso del boom ("el boom terminó con el bombardeo a la Moneda") ya que "el 11 de septiembre de 1973 hizo irreversible la venida de un periodo histórico en el que las dictaduras vaciarían la modernización de todo contenido progresista, liberador" (Avelar 55).

Sin embargo podríamos extendernos hacia otras fechas desde una perspectiva más latinoamericana (que además se encuentra en la vocación latinoamericana de la Revolución cubana, manifestada en su apoyo y cooperación a varios grupos) y considerar 
dos "olas" o "generaciones" 1 del brote de la izquierda armada. Dentro del arco que va desde la entrada de Fidel en La Habana el 8 de enero de 1959 hasta el inicio de la década de 1990 signado por varias derrotas, se extienden, en el lapso de treinta años, las dos generaciones. En la primera ola que abarca los movimientos guerrilleros de los sesenta y principios de los setenta, el centro de gravedad está en el Cono Sur con los protagonismos del Movimiento de Liberación Nacional Tupamaros de Uruguay que representó el primer grupo guerrillero con impacto latinoamericano entre los que surgieron en el sur luego del triunfo de Castro, y con la llegada al poder en Chile de la Unidad Popular y Salvador Allende en 1970 (con el “apoyo crítico” del Movimiento de Izquierda Revolucionaria-MIR), para citar sólo dos ejemplos. Estos procesos encontrarán su fin en el endurecimiento de la dictadura en Brasil en 1968 y en los golpes de estado en Chile (1973), Uruguay (1973) y Argentina (1976), donde la brutal represión impulsada por las doctrinas de seguridad nacional aplasta a la izquierda armada. El centro de gravedad pasa, entonces del sur hacia el norte, dando lugar a una segunda ola de brotes de la guerrilla desde fines de los setenta y durante la década de los ochenta, cuya presencia en Centroamérica y el Caribe (las islas de Jamaica y Granada) se hace notable. Ciertos grupos protagonizan este recorrido que va de los setenta a su cierre en los inicios de los noventa: así, por ejemplo, el Ejército Guerrillero de los Pobres (EGP) de Guatemala, creado en 1973 que fue-junto con otros grupos-violentamente reprimido y quebrantado entre 1982 y 1983; o el Frente Farabundo Martí para la Liberación Nacional (FMLN) de El Salvador que adquirió notoriedad por su capacidad militar en los ochenta y que en 1992 firma el Acuerdo de Paz que lo condujo a la legalidad como partido político; o el Frente Sandinista de Liberación Nacional (FSLN) en Nicaragua cuya resonante victoria, la "revuelta idílica”, data de 1979 y marca, veinte años después de Cuba, la posibilidad del triunfo armado en América Latina, y que luego es derrotado en las urnas en 1990 frente a Violeta Chamorro. Asimismo, en 1992 es capturado Abimael Guzmán Reynoso, el principal cabecilla del Partido Comunista del Perú-Sendero Luminoso (PCP-SL). La caída del Muro de Berlín en 1989 y la paulatina desintegración del bloque socialista de la URSS, como fechas del reloj internacional, impactaron también en la debacle de la izquierda revolucionaria y constituyeron un punto de inflexión en la revolución cubana que dio inicio en 1990 al denominado "Período Especial en Tiempo de Guerra”. De este modo, 1990 se abre con otro horizonte que recoloca a la izquierda

1 Esta distinción en dos o más olas o generaciones, que entraña una serie de cambios en los modos de operar de los grupos armados de izquierda, aparece en Timothy Wickham-Crowley, Guerrillas and Revolution in Latin America: A Comparative Study of Insurgents and Regimes since 1956; en Jorge Castañeda, La utopía desarmada. El futuro de la izquierda en América Latina; en James Petras en "Neoliberalismo en América Latina: la izuierda devuelve el golpe”, entre otros. De todos modos, aquí sólo nos interesa marcar algunas fechas claves de la "derrota", que intervienen en el imaginario e impactan en el campo cultural.

$\begin{array}{llllll}\text { Revista Iberoamericana, Vol. LXXX, Núm. 247, Abril-Junio 2014, } & \text { 327-349 } \\ \text { ISSN 0034-9631 (Impreso) } & \text { ISSN 2154-4794 (Electrónico) }\end{array}$ 
armada latinoamericana -ya sea aquella que ha sufrido la derrotas por las armas o que ha virado su política hacia la legalidad democrática- en el contexto internacional del derrumbe del bloque socialista y en el contexto local signado por una ola democrática ${ }^{2}$ y por los reclamos en favor de los derechos humanos.

En este nuevo escenario de recambio de valores y políticas, una serie de textos literarios va a reflexionar en torno a la reciente experiencia de la lucha armada: estas escrituras de la derrota van a asediar, con tenaz insistencia, desde uno y otro flanco los saberes de la literatura, los registros vigentes de diversas estéticas, los protocolos de variados géneros y discursos, para ensayar nuevas vías. Estas narrativas de la derrota van a configurar una zona importante de los imaginarios de fines del siglo xx, van a tramar una "era imaginaria” en el sentido que José Lezama Lima le otorga a la capacidad de la literatura para tejer la historia a través de la imagen, y para ofrecer alternativas a otros discursos sociales. En el campo de la crítica literaria latinoamericana, varios trabajos han estudiado las escrituras de la derrota. Recorrer algunos de ellos, sin intención de agotarlos, nos permite advertir algunas de las principales líneas de lectura y recoger ciertas ideas-fuerza, ciertos conceptos-guía que ofician de columna vertebral en los debates y que podemos reordenar en los siguientes pares: derrota/fracaso; duelo/melancolía, y desencanto/desarme.

\section{DerRota, MELANColía y DESARME}

\section{Derrota/ fracaso}

Una primera distinción entre fracaso y derrota es indispensable para el deslinde de dos focos, e incluso de dos tradiciones, dentro de la literatura latinoamericana. Ana María Amar Sánchez, en Instrucciones para la derrota. Narrativas éticas y políticas de perdedores, se ocupa de diferenciar ambos espacios. Mientras la derrota tiene una dimensión política y un anclaje histórico, el fracaso carece de esa estrecha y definitoria conexión política con el contexto. Los agentes de ambos suelen ser diferentes: si el perdedor político puede convertir su derrota en un triunfo ético; el fracasado muestra señas de degradación, humillación o abyección. En esta línea, la derrota no se percibe como un fracaso, sino como una batalla perdida y allí es donde parece situarse la mirada de Amar Sánchez cuando privilegia la figura del “perdedor ético” quien no ha renunciado a sus ideales y se mantiene expectante a la espera de una coyuntura histórica más favorable. Instrucciones para la derrota interroga las formas en que la literatura

2 En los noventa, además, se completa el final de las dictaduras del Cono Sur con las aperturas hacia la transición democrática en Chile (1990) y Paraguay (1990), que vinieron a concluir las democratizaciones de Bolivia (1982), Argentina (1983), Uruguay (1985) y Brasil (1985).

Revista Iberoamericana, Vol. LXXX, Núm. 247, Abril-Junio 2014, $327-349$
ISSN 2154-4794 (Electrónico) 
ha representado las figuras del perdedor político, sus modos de leer y convivir con la pérdida, las vías de afrontar las derrotas, en tanto los textos ofrecen opciones imaginarias, alternativas y divergentes a las soluciones simplificadoras de ciertos discursos políticos y mediáticos. Amar Sánchez abandona el perfil negativo de la pérdida para resaltar su potencial político, la derrota no es solo aquello que ha acontecido sino un principio activo y dinámico que abre alternativas y define prácticas políticas, un acontecimiento que desafía al sujeto -¿qué proyectos construir sobre las ruinas de los vencedores?- y lo interpela a elegir entre las diversas estrategias de sobrevivencia que van desde el acomodo al nuevo contexto hasta su rechazo.

Así, la figura del perdedor abre un abanico de respuestas ante la derrota: la resistencia, el desencanto, la melancolía, la nostalgia, el conformismo, la resignación, el pesimismo, la esperanza. Pero Amar Sánchez elige y se detiene en ciertas figuras que recorren los textos literarios: el "perdedor ético"; el "vencedor" y el "perdedor desencantado", entre otros.

El "perdedor ético" -un antihéroe de estos tiempos crepusculares- se destaca en la escena de la derrota política y desempeña una de las opciones más fuertes: se retira de la participación política dominada por los vencedores y hace de este repliegue un puntal de resistencia, en esta línea se acerca a la figura del intelectual que para Edward Said es siempre un exiliado, o a la defensa que hace Hannah Arendt de la vida contemplativa del pensamiento, del retiro en soledad y de la negativa a participar, o a la predilección por la distancia y la prescindencia como políticas alternativas al poder estatal en Theodor Adorno. El antihéroe reconvierte la pérdida en un triunfo ético, y se aleja de la resignación o la nostalgia. Esta distancia, repliegue o retirada no es desinterés ni pasividad sino una voluntad por articular una apuesta política desde otro lugar no ligado a la centralidad del Estado, ni a los modos tradicionales de ejercer la política. Para pensar desde otro lugar estas prácticas políticas de los perdedores, reactivas a todo pacto, Amar Sánchez dialoga con una serie de perspectivas teóricas recientes sobre el poder -tales como los conceptos de lo "impolítico", la "biopolítica” y la "metapolítica”- a través de las cuales Roberto Esposito, Giorgio Agamben, Alain Badiou, Michel Onfray y Jacques Rancière buscan nuevos filtros para razonar lo político. La reconfiguración de aquellos vínculos entre ética y política que subordinan la ética a los fines últimos de la razón de Estado, que anteponen los fines a los medios, constituye otro de los desafíos que los perdedores asumen. La defensa de una ética insumisa al poder, rebelde y disidente, cifra la paradójica dimensión épica de este antihéroe perdedor que defiende la razón de los vencidos.

Además del "perdedor ético", las ficciones ofrecen otras opciones del perdedor: aquellos que se adaptan y acomodan para sobrevivir, quienes traicionan las banderas y abjuran de sus ideales, y los escépticos o desencantados. Finalmente los "vencedores" suelen exhibir una identidad incierta, lábil y borrosa, o muestran las señas del burócrata de la banalidad del mal que Hannah Arendt describió, o presentan su perfil "infame" y "criminal”.

Revista Iberoamericana, Vol. LXXX, Núm. 247, Abril-Junio 2014, $327-349$
ISSN 0034-9631 (Impreso) 
En el centro del trabajo crítico y analítico de Amar Sánchez, se encuentra el interés por auscultar la "ética de la escritura" a través de la cual la voz del texto asume su posición ético-política. Si bien la mayoría de los textos del corpus elegido se colocan del lado del perdedor ético, también aparecen ciertos textos que se ubican del lado del vencedor como Historia de Mayta de Mario Vargas Llosa en la cual el perdedor es "patético" y "despreciable”; o se vuelve ambiguo adoptando una posición lábil y poco definida como en Soldados de Salamina de Javier Cercas. En esta "ética de la escritura" se percibe el interés central del trabajo de Ana María Amar Sánchez por leer los vínculos de la literatura con las dimensiones ético-políticas.

Idelber Avelar (Alegorías de la derrota: la ficción posdictatorial y el trabajo del duelo) también analiza el impacto de la "derrota" en la literatura posdictatorial del Cono Sur, desde una perspectiva que se focaliza más que en el nivel de la representación, en las dimensiones estéticas e institucionales de la literatura latinoamericana. En esta línea, la derrota irrumpe como una experiencia que quiebra la maquinaria literaria del boom latinoamericano con sus realismos mágicos, maravillosos y fantásticos, y corroe el discurso redentorista del intelectual latinoamericano para dar lugar a la emergencia de la "alegoría". Avelar, entonces, coloca a la derrota como un dispositivo que introduce nuevas condiciones en la escritura y por ello instaura un corte en la literatura latinoamericana. Considera una doble derrota: la derrota de la izquierda latinoamericana cuyo emblema es la caída de Allende en 1973 y el inicio de las dictaduras en el Cono Sur; y la sustitución del Estado Nacional moderno por el mercado transnacional posestatal que acompañó a los procesos dictatoriales.

Varias de las características definitorias del boom se astillan ante la experiencia de ambas derrotas. La planetarización del mercado transnacional que desarma las oposiciones entre lo moderno y lo premoderno por un lado, y la fractura que la derrota impuso al discurso latinoamericano redentorista por el otro, protagonizan el quiebre de las políticas de los realismos mágico-maravillosos basadas en el vínculo (que en un mismo gesto subalterniza y salva al "otro") entre el mundo moderno de la enunciación y el mundo premoderno mágico o maravilloso del enunciado. La alegoría vehiculiza la desintegración de esta polaridad (provocando una inmanentización de aquella alteridad fantástico-mágica que irrumpía la normalidad) y expone el dominio de una sola lógica comandada por el horror ("la alegoría tiene lugar cuando lo siniestro se ha vuelto él mismo familiar"). En esta economía de la pura inmanencia, los espacios alternativos (del afuera) en los cuales anclar un principio explicativo o un fundamento último que recupere una totalidad coherente, y desde los cuales fraguar las políticas de resistencia, parecen esfumarse. En esta lógica, la experiencia del horror se vuelve irreductible a un principio explicativo, escapa al discurrir de una historicidad progresiva, reescribe la historia como ruina y derrota, permanece indecible e indescifrable, y provoca el fracaso en la lectura en su intento por alcanzar una interpretación acabada. Lo que supone la

\footnotetext{
Revista Iberoamericana, Vol. LXXX, Núm. 247, Abril-Junio 2014, 327-349 ISSN 0034-9631 (Impreso) ISSN 2154-4794 (Electrónico)
} 
sustitución del símbolo con su principio de unificación e integración de una totalidad infisurada (que ha dado lugar a los discursos de la identidad latinoamericana en el interior del boom) por la alegoría que sólo cuenta con los fragmentos y restos (las ruinas que Benjamin anotó) dejados por la derrota.

En esta economía de la escritura posdictatorial, Avelar incluye un paso más que la derrota solicita: la necesidad del duelo y la vocación testimonial de la escritura frente al objeto perdido. En esta línea, la alegoría resulta una estética privilegiada para cifrar el objeto perdido que aún se encuentra vivo en la cripta, su carácter fantasmático y espectral, para intentar una imposible restitución, como quería Benjamin.

En diálogo con las propuestas de Walter Benjamin, Avelar pone a funcionar la alegoría en la posdictadura del Cono Sur para explorar las nuevas trazas que la derrota ejerce en la ficción. La alegoría es, entonces, para Avelar, la faz estética de la derrota política.

Tanto el libro de Amar Sánchez como el de Idelber Avelar indagan, entonces, el impacto de las derrotas políticas en la literatura latinoamericana, aunque desde diversas y complementarias perspectivas. Si en Ana María Amar Sánchez, la derrota es leída desde el vínculo entre la escritura literaria y las prácticas ético-políticas para iluminar el protagonismo de la figura del perdedor ético y sus estrategias de resistencia; en Avelar, la derrota es analizada en el interior de la tradición literaria latinoamericana en tanto cuestiona el estatuto de la escritura literaria vigente en los realismos mágicos, maravillosos y fantásticos del boom, para reinstalar la alegoría. Mientras el foco de Amar Sánchez privilegia rastrear las tácticas de resistencia de los perdedores en un corpus textual que recorre América Latina (y se extiende hasta España); Avelar se inclina al estudio de las economías del duelo frente al objeto perdido en el territorio del Cono Sur. En cambio Poéticas del fracaso, el volumen que coordinan Yvette Sánchez y Roland Spiller apunta a la idea de "fracaso", sin descuidar también las derrotas políticas.

El concepto de fracaso es aún menos preciso que el de derrota, ya que por un lado coexisten diversas perspectivas sobre el fracaso y además esta categoría se abre a otros escenarios y vínculos. Respecto a la idea de derrota, el fracaso no remite única o necesariamente a una causa política, ni tiene una raíz histórica, aunque ambas pueden estar. Mientras en la derrota un acontecimiento histórico interpela al sujeto desde cierta exterioridad, el fracaso atañe a la interioridad del sujeto, comprometiendo la responsabilidad, la voluntad o la libertad de elección en ese nudo de frustración. No obstante, más que una distinción conceptual nos interesa revisar la deriva del fracaso en la literatura. En Poéticas del fracaso, despuntan dos líneas del fracaso en la literatura. Por un lado, la tradición literaria del escritor fracasado, que ha calado en la literatura rioplatense en escritores como Arlt y Onetti, en textos como "Escritor fracasado" (dentro de El jorobadito) y El pozo, piedras fundantes de esta mitología que otros han continuado. En sus respectivos capítulos del volumen, Sergio Chejfec ("El fracaso como círculo virtuoso”) e Yvette Sánchez (“Una red de conspiradores del fracaso”) arman un

\footnotetext{
Revista Iberoamericana, Vol. LXXX, Núm. 247, Abril-Junio 2014, 327-349 ISSN 0034-9631 (Impreso) ISSN 2154-4794 (Electrónico)
} 
parnaso de fracasados, una galería de autores sobre el fracaso -Arlt, Borges, Laiseca, Salazar Bondy, Onetti y Aira- y también una lista de antihéroes ficticios -Bartleby, Silvio Astier, entre otros-.

Por otro lado, varios trabajos indagan las poéticas del fracaso o el fracaso de la escritura que tiene diversas articulaciones, tales como: el fracaso de la representación mimética que la literatura supone; el fracaso como pulsión creativa tanto a nivel de imaginarios -el naufragio, la caída, la derrota, el desencanto, la ruina, el derrumbe, el colapso- como de poéticas caracterizadas por la ruptura, la distorsión, lo trunco.

El fracaso de la escritura ante el relato del horror y frente a la vocación testimonial es uno de los nudos que la crítica más ha abordado y debatido. Amar Sánchez analiza el desafío de narrar el mal que esta narrativa enfrenta, apuesta claramente por la potencia de la escritura que debe lidiar con esa imposibilidad de narrar, destaca la voluntad por terminar con el punto muerto de lo indecible del que habla Michel Onfray, y enfatiza la vocación de testimoniar, aun cuando todo testimonio contenga en su centro algo que es intestimoniable (Agamben), ya que la escritura acarrea el trabajo de la memoria.

\section{Duelo/ melancolía}

Los conceptos de “duelo” y “melancolía” han servido para reflexionar sobre diversos modos de tramitar las pérdidas (desde los ideales revolucionarios de los sesenta hasta el “desaparecido”). ${ }^{3}$ En algunos debates en el Cono Sur, ambos conceptos configuran metáforas de procesos y prácticas de la memoria colectiva o social, y por ello la apuesta por el duelo o la melancolía permite iluminar ciertas tensiones en el interior de la izquierda en, por ejemplo, la posdictadura argentina que aquí elegimos enfocar, entre otras líneas posibles del debate.

El trabajo de Sigmund Freud (Trauer und Melancholie, 1915) constituye el punto de partida, el grado cero al que se regresa y desde el cual se articulan las posiciones alternativas del duelo o de la melancolía. Freud reclamóla necesidad de estudiar en paralelo ambos procesos en tanto respondían a una situación inicial análoga de pérdida, aunque luego adquieren un diferente desenlace que en un caso (el duelo) resultaba "normal” mientras en el otro (la melancolía) se volvía un “cuadro patológico”. Ambos estados comienzan con una "pérdida” (de un ser amado, de una abstracción equivalente como la patria, la libertad, el ideal; o incluso de un objeto que se sustrae a la conciencia). En

3 El par "duelo-melancolía" ha sido objeto de diversas reflexiones que desplazan los saberes del psicoanálisis a las prácticas sociales. Si bien esta extrapolación de un sistema (el psicoanálisis) a otro (la memoria colectiva) ha recibido numerosas críticas sobre su consistencia, sí en cambio ha servido como espacio de reflexión sobre las prácticas simbólicas, presuponiendo una "analogía" no reduccionista entre ambos sistemas. Ver Vezzetti: "Derechos humanos y psicoanálisis.”

Revista Iberoamericana, Vol. LXXX, Núm. 247, Abril-Junio 2014, 327-349 ISSN 0034-9631 (Impreso)

ISSN 2154-4794 (Electrónico) 
la labor del duelo, el yo reconoce que el objeto amado ya no existe y en consecuencia inicia el costoso proceso de sustracción de la libido del objeto, el abandono de sus ligaduras con el mismo, hasta que el principio de realidad termina por imponerse, y el yo queda libre y exento de toda inhibición para elegir un nuevo objeto. En cambio, en la melancolía la pérdida se vuelve sobre el yo, la libido libre no es desplazada a otro objeto sino retraída al yo, atrapada en las redes de su elección narcisista, sin lograr una retracción de las investiduras necesarias para el establecimiento del estado de reposo. Es por ello que el complejo melancólico se comporta como una "herida abierta" y se resiste al "deseo de dormir del yo"; mientras el duelo reconoce que el objeto ya no existe, elige renunciar al mismo y cortar su ligamen con él.

Las reflexiones sobre el duelo y la melancolía, que adquieren relevancia en el contexto de las posdictaduras del Cono Sur, se focalizan en el objeto perdido (cuya figura central es el desaparecido pero también la derrota de la izquierda) y se resisten a pensar el duelo en términos de un proceso cerrado que supone la sustitución de la pérdida por otro objeto; por ello es posible advertir la progresiva importancia que la melancolía (en detrimento del duelo) va adquiriendo en estas reflexiones.

En Alegorías de la derrota: la ficción posdictatorial y el trabajo del duelo, Idelber Avelar señala el imperativo del duelo en la literatura de la posdictadura como una vía -aunque imposible- de restituir la pérdida. Progresivamente se va despegando de los límites en los que Freud define al duelo: para Avelar se trataría de un duelo en suspenso, incumplido, que se resiste a enterrar y a sustituir el objeto perdido, y que por ello se acerca a la melancolía. Pone a dialogar diversas perspectivas teóricas sobre el duelo que insisten en su carácter sedicioso, inacabado, activo (lejos del reposo final del que Freud habla): recupera el valor del duelo como un afecto y efecto perturbador del orden de la polis en Platón; retoma la idea de "olvido activo" en Nietzsche para explorar la posibilidad de un "duelo afirmativo", distante tanto de un "duelo depresivo" como de un "duelo triunfante"; rescata las reflexiones de Nicolás Abraham y María Torok sobre la idea de cripta en la cual el objeto perdido es enterrado vivo, sustrayéndose así a la pérdida, y convirtiéndose en una persistencia fantasmática de un duelo irresuelto (que solo puede representarse en la lengua críptica de la alegoría); y finalmente cala en la idea benjaminiana de una deuda contraída con las derrotas del pasado, deuda que demanda una tarea de restitución, y que en la escritura literaria debe lidiar con el abismo abierto entre el imperativo de narrar y la experiencia del horror. Así, Avelar complejiza la factura del duelo que protagoniza la literatura de la posdictadura, advierte sobre la imposibilidad de reunir experiencia y narrativa, e indica la presencia del "agujero negro" en la función restitutiva del duelo. Finalmente propone, en su análisis sobre En estado de memoria de Tununa Mercado, una "melancolía crítica" en su capacidad para activar una práctica crítica que se niega a los mecanismos sustitutivos o compensatorios, y se sitúa en el abismo de la melancolía.

\footnotetext{
Revista Iberoamericana, Vol. LXXX, Núm. 247, Abril-Junio 2014, 327-349 ISSN 0034-9631 (Impreso) ISSN 2154-4794 (Electrónico)
} 
Christian Gundermann en Actos melancólicos. Formas de resistencia en la posdictadura argentina parece situarse en el punto final del texto de Avelar y potenciar la idea de "melancolía" que lo cierra. Parte, entonces, de la contundente negación del sujeto melancólico a aceptar que el objeto amado se haya perdido. Desde allí configura la noción de "acto melancólico" como una posición crítica y una práctica política de resistencia frente a la "revolución conservadora” y a la “cultura de desaparición”(Virilio) desatada al ritmo de la dictadura y del neoliberalismo en Argentina. Dialoga, en especial, con las nuevas conceptualizaciones sobre la melancolía de Judith Butler, Gillian Rose, Nicolás Abraham y María Torok, entre otros. Recupera la "melancolía combativa” y el paradójico “trabajo melancólico" de Judith Butler (Antigone’s Claim) como herramientas de transformación que operan sobre la ley y la comunidad, alejándose del estatismo que Freud le atribuyó a la melancolía y de aquellas concepciones que han considerado la actitud melancólica de la posdictadura como síntoma de la inacción, el retraímiento o la ineficacia. La lectura que Gillian Rose (Mourning Becomes the Law) hace sobre el mito de Phoción, un mártir sentenciado y asesinado por un tirano, constituye otra metáfora sobre el potencial político de la melancolía que se opone al duelo y al olvido: la esposa de Phoción se traga las cenizas de su marido difunto y con ello provoca la reconfiguración de la ley de la comunidad. ${ }^{4}$

El "acto melancólico" en su rechazo a aceptar la pérdida del objeto, emblematiza las prácticas de la "nueva izquierda melancólica y revolucionaria" de las Madres de Plaza de Mayo y de HIJOS, quienes se resisten a cortar los vínculos con los desaparecidos, reclaman su "reaparición con vida", rechazan el duelo como una política del olvido y se niegan a aceptar la derrota política de la izquierda. En este sentido, la "melancolía" rotura una posición de la izquierda nucleada en torno a Madres de Plaza de Mayo en la línea de Hebe de Bonafini y a HIJOS que procura recuperar varias de las consignas de la lucha revolucionaria de los setenta y se niega a colocar la derrota como un momento fundante de un nuevo contexto político y cultural abierto con la democracia. En cambio la defensa del "duelo" por parte de Hugo Vezzetti y la izquierda nucleada en torno a la revista Punto de vista dirigida por Beatriz Sarlo, configura otro polo de la izquierda argentina que evalúa la "derrota” en otros términos. Esta postura constituye uno de los focos de ataque de Gundermann, quien llega a considerar la posición de Vezzetti como una adhesión a las políticas de la democracia neoliberal, una conformidad con las leyes

4 Desde estas perspectivas, Gundermann recorre un corpus heterogéneo, centrado en el cine y la literatura argentina de los '80 y los '90, integrado por algunos films como La amiga (1988) de Jeanine Meerapfel, Gatica el mono (1992) de Leonardo Favio, el revolucionario Cine Liberación de Pino Solanas, El amor es una mujer gorda (1987) y Buenos Aires viceversa (1996) de Alejandro Agresti; la obra teatral Antígona furiosa (1986) de Griselda Gambaro; la poesía de Néstor Perlongher; y ciertas novelas como La cátedra (2001) de Nicolás Casullo y Nadie nada nunca (1980) de Juan José Saer, entre otras.

Revista Iberoamericana, Vol. LXXX, Núm. 247, Abril-Junio 2014, $327-349$
ISSN 2154-4794 (Electrónico) 
de olvido e impunidad, y la aceptación de la derrota de la izquierda. ${ }^{5}$ Resulta difícil estar de acuerdo con esta postura crítica que Gundermann esgrime respecto a Vezzetti y a Punto de vista. Un repaso por las reflexiones de esta otra izquierda argentina nos conduce a vislumbrar los alcances de la asunción de la pérdida y la derrota como dispositivos para la autocrítica, y de las significaciones del “duelo” para el contexto del momento. Lo cierto es que este debate pone en escena el protagonismo de la "derrota” como uno de los dilemas que tensa y diferencia las posiciones de la izquierda.

El artículo "Variaciones sobre la memoria social” de Hugo Vezzetti condensa con gran claridad su perspectiva frente al duelo, que luego amplía y expande en su libro Pasado y presente. Guerra, dictadura y sociedad en la Argentina (2002). Allí elige el trabajo del duelo como alternativa a dos posiciones de las cuales se distancia: la amnesia de quienes se proponen "dar vuelta la página” en una clara política del olvido que cancela el pasado y lo clausura para el presente; y la alucinación o el exceso de la memoria que reactualiza de modo inmediato el pasado, responde a una visión heroica de los militantes y los fusiles caídos que aguardan ser nuevamente empuñados, y pretende retomar el combate en esa misma escena congelada, con lo cual también vacía el pasado al colocarlo plenamente en el presente. En cambio el duelo se ofrece como un trabajo: reintegra algo como perdido e irrecuperable a la vez que lo traslada a otra dimensión, de modo que el crimen queda abierto a la elaboración, la simbolización y la redención en el presente. Así, el duelo se articula como un trabajo de rememoración, capaz de tramitar el núcleo traumático de la pérdida, ${ }^{6}$ y colocar el pasado en una red más abierta de sentido, para situarlo como punto de partida de un nuevo ordenamiento de ideas, propósitos y programas, que -para Vezzetti- se abre con la democracia y la defensa de los derechos humanos. El duelo, entonces, está señalando una distancia respecto de ese pasado de la dictadura y de los valores e ideologías que atravesaron a la izquierda insurgente: el duelo supone, por un lado, que el inicio de la democracia, el juicio a los militares y la publicación del Nunca Más inauguraron una nueva etapa protagonizada por los valores de la democracia y los derechos humanos; y por el otro, el duelo implica

5 Véase “A mi modo de ver, este mandato ‘ético’ del duelo, su supuesta sobriedad madura (o ‘construcción trabajosa’ en los términos de Vezzetti), su ‘haber elaborado’ la relación con el pasado, se ha tomado como excusa para la aceptación de la derrota de la izquierda y para la aquiescencia con la forma limitada y autoritaria de la democracia neoliberal. Insistir en el duelo, es decir, exhortar un proceso que apunta la aceptación de la pérdida es poco menos que un apoyo directo al olvido y la impunidad en un contexto en que un presidente (Menem) inicia su gobierno con el acto fundador del indulto a los represores al mismo tiempo que intensifica la política económica inaugurada por los militares [...]” (20).

6 Vezzetti parte de la concepción freudiana del olvido como trauma que es necesario tramitar, lo que supone que el síntoma es a la vez la amnesia y el recuerdo intensificado de un suceso determinado: aquello que en la experiencia consciente es amnesia y desconocimiento, en otra escena inconsciente es recuerdo vivo que el síntoma repite como algo inmodificable y que está disponible para ser evocado por un acto de memoria.

Revista Iberoamericana, Vol. LXXX, Núm. 247, Abril-Junio 2014,
ISSN 0034-9631 (Impreso) 2154-4794 (Electrónico) 
una revisión y autocrítica por parte de la izquierda respecto a sus ensueños mesiánicos y sus políticas de la violencia.

Esta posición implica un reconocimiento de la pérdida, del fracaso y de la derrota no para quedarse atrapado en ellas, sino para activar la dimensión "antitotalitaria" (socavando las certezas de "destinos manifiestos" y las exaltaciones de la propia grandeza) que es posible recuperar de la experiencia del horror, y que puede constituirse en pivote de un nuevo pacto fundacional, de una nueva cultura ética-democrática. En esta ecuación, la dictadura inscribe un corte, deviene un parteaguas entre dos épocas, como una experiencia que fracturó el ideal fundacional de la Nación y reclama reconstruir un nuevo pacto fundacional, ahora bajo otros principios que se nuclean en torno a los derechos humanos. En cambio, la "nueva izquierda melancólica y revolucionaria" de las Madres de Plaza de Mayo y de HIJOS, sin desconocer los cambios introducidos por la democracia, están más atentos a rediseñar nuevos modos del activismo político, y se vinculan con/y repolitizan algunas consignas de la izquierda revolucionaria.

\section{Desencanto/ desarme}

“Desencanto” y “desarme” son términos que exhiben-desde el prefijo de inversióntodo un proceso de revisión, despojo y deconstrucción de los discursos “encantados” y "armados" de los sesenta; presuponen las creencias en lautopía y en la lucha revolucionaria para postular el fin de las mismas y un ajuste de cuentas con la revolución continental en la que creyeron, y dibujan el itinerario que va (simbólicamente) de 1959 a 1989.

Jorge Fornet en Los nuevos paradigmas (2006) explora, por un lado, los nuevos paradigmas surgidos en la literatura latinoamericana por la influencia del rock, de MTV, de la cultura del video, del espacio virtual, del protagonismo del cuerpo, entre otros (visibles en el grupo chileno McOndo, en el Crack mexicano y en los "novísimos" cubanos); y, por el otro, las "narrativas del desencanto" que expresan una desilusión respecto de la revolución en América Latina de los años sesenta, en especial la revolución cubana. No se trata, en el interior de la literatura cubana, de la "narrativa anticastrista" sino de aquella literatura que da cuenta del tránsito que va de los ideales utópicos al desencanto de los mismos, que siente la frustración del "sueño de una nueva sociedad y de un hombre nuevo" (6); escrita en general por narradores nacidos antes de 1959, y que están atravesados por el trauma histórico y la crisis de valores que supuso el fracaso del socialismo en Europa del Este y el consiguiente reajuste cubano del proyecto nacional ante esta nueva situación.

Es posible pensar el acontecimiento del desarme también desde el centro mismo del campo cultural cubano. El "desarme" también dibuja un recorrido que comienza con el intelectual y el escritor "armado" en el escenario de los ciclos revolucionarios desplegados en torno a la Revolución cubana y bajo los fuegos desatados en el clima

\footnotetext{
Revista Iberoamericana, Vol. LXXX, Núm. 247, Abril-Junio 2014, 327-349 ISSN 0034-9631 (Impreso) 
de la Guerra Fría. La figura de Calibán como emblema del intelectual que maldice con su palabra volcánica y el mismo ensayo de Roberto Fernández Retamar (Calibán 1971), que configura una trinchera de papel - diría José Martí- cuando contrapone las facciones intelectuales en disputa en el campo latinoamericano (la Anti-América y la América legítima) a través de la polaridad amigo/enemigo, cifran en gran medida el perfil del escritor e intelectual armado.

En la década de los noventa asistimos a su desarme propiciado por la desarticulación de los esquemas amigo/enemigo para rearticular las heterogeneidades que habitan los Estados nacionales, por el abandono de las macronarrativas redentoristas para abrirse a los múltiples relatos menores que se cruzan en los diversos territorios, por la transformación de su verba volcánica y de la violencia simbólica en diálogo y conversación. El propio Fernández Retamar inicia en Todo Calibán, publicado en 1989, el desarme y reescritura del personaje emblema Calibán y luego los ensayistas cubanos de la generación del '89 se ocuparán de cuestionar y desarmar -desde otro lugar- el proyecto intelectual revolucionario que Calibán presupone (Basile 2012).

Narrativas de la derrota, de la melancolía y del desarme, la ficción de las últimas décadas parece poder explicarse a través de palabras que apuntan a diversas inflexiones de la catástrofe; y posiblemente el punto extremo de esta mirada se encuentre en los textos que pueden ser leídos bajo el signo del apocalipsis. En los ensayos compilados por Geneviève Fabry, Ilse Logie y Pablo Decock en Los imaginarios apocalípticos en la literatura hispanoamericana contemporánea, el mito del apocalipsis permite desplegar un imaginario muy presente en la literatura latinoamericana que se radicaliza a partir de las traumáticas experiencias históricas sufridas y genera múltiples representaciones de la violencia padecida en América Latina. En la producción del Cono Sur, en particular, la figura del Apocalipsis parece ser el eje vertebral de numerosos textos, tanto en sus aspectos temáticos como formales. Fabry y Logie subrayan que las reescrituras más interesantes producidas a partir del mito contienen una doble búsqueda: la de una comprensión de su contexto histórico y la de los medios para narrarlo. El discurso apocalíptico ha configurado a todo lo largo del siglo xx imágenes del colapso de la modernidad en América Latina y los textos de Cortázar, Rulfo, Cardenal, Arguedas proponen ya representaciones políticas en las que la poscatástrofe funciona como un instrumento conceptual fundamental. Pero en la perspectiva de este trabajo, autores posteriores como Vallejo, Bolaño, Cohen representan el ingreso en la literatura de un registro absolutamente nuevo del imaginario apocalíptico. Y con el surgimiento en los noventade escritores como Chejfec, Kohan, Becerra y en especial Ferreyra nos encontramos con una literatura que puede considerarse "más allá del apocalipsis". Estas representaciones posapocalíticas se preguntan si hay un sentido después del final; en ellas dominan las ruinas y se pone en escena la conciencia de un "final" definitivo para

Revista Iberoamericana, Vol. LXXX, Núm. 247, Abril-Junio 2014, $327-349$
ISSN 0034-9631 (Impreso) 
toda una cultura. ${ }^{7}$ Una narrativa apocalíptica -o posapocalítica- que no sólo funciona como una metáfora de un mundo visto con desencanto, como un espacio del fracaso absoluto, sino que implica nuevas formas estéticas que acompañan ese proceso. ${ }^{8}$

\section{EL TRABAJO DE LA DERROTA}

Varios de los trabajos compilados aquí revisan diversos aspectos de las narrativas de esos años noventa: desde las reconfiguraciones estéticas como el "realismo inseguro" de Marcelo Cohen”; el "realismo visceral” de Roberto Bolaño, y el "esperpento lemebeliano” con su “poética neobarrocha” (que oficiarán de reemplazo del boom de la narrativa latinoamericana con sus diversas tendencias como el macondismo, el realismo mágico, lo real maravilloso, etc.); o la presencia de imaginarios y "gramáticas para los mitos provisorios del nuevo futuro” -tal como reclama Cohen- en torno al tedio, el aburrimiento, la abulia (Busqued, Avalos Blacha, Iosi Havilio, Hernán Rosino), a la figura del escritor melancólico (Bolaño), a las ruinas (Ponte), al naufragio (De la Nuez); o las geografías y los mapas de las políticas de la violencia por parte de los Estados que van enhebrando las dictaduras latinoamericanas con los fascismos europeos (Bolaño); o los desplazamientos y fugas que emprende la figura de Calibán -emblema de los valores de la revolución cubana- en los noventa. Implican, además, una nueva interpelación a los vínculos entre literatura, política y ética, cuya reflexión debe sopesar y evaluar ciertas ideas fuerza vigentes en esos años.

Los artículos reunidos en esta antología configuran una apretada malla de relaciones en cuanto a sus perspectivas y a sus coincidencias teóricas; en este sentido, establecer clasificaciones que los separen y “ordenen” se vuelve díficil e incluso arbitrario. Por este motivo, esta presentación intenta establecer articulaciones entre ellos, señalar caminos,

7 Fernando Reati llama "literatura de anticipación” a la narrativa que -ya sea ciencia-ficción, políticaficción, antiutopía o distopía- se proyecta hacia el futuro y, al anticipar posibles direcciones de la historia, ilustra las transformaciones de la Argentina en la década de los noventa, durante el imperio del neoliberalismo y la globalización. En este sentido hay puntos de contacto teórico-críticos, e incluso de textos y autores, entre el estudio de Fabry y Logie y el de Reati.

8 Estéticas y prácticas diferentes son también las que Reinaldo Laddaga llama de emergencia para referirse a la formación de otra cultura en el campo de las artes hacia finales del siglo xx y comienzos del xxI. Según su análisis, este cambio es sólo comparable a la transición que tuvo lugar entre finales del siglo XVIII y mediados del xix durante la conformación de la modernidad estética. En el actual proceso de globalización, la exploración artística implica abandonar la mayor parte de los gestos, las formas, las operaciones heredadas de la cultura que se había constituido a partir de los últimos años del siglo XviII. El presente entonces está definido por la proliferación de proyectos que renuncian a los modos de producción de las obras de arte que caracterizaron a las vanguardias y en general al arte de la primera mitad del siglo xx; esta proliferación se acelera en los noventa y no es indiferente a "la multiplicación de 'signos de obsolencia' de una cierta tradición moderna y a 'la caída de intensidad en la fe en esa cultura de las artes' que se formaba en el curso de los siglos XIX y xx” (22).

Revista Iberoamericana, Vol. LXXX, Núm. 247, Abril-Junio 2014, 327-349 ISSN 0034-9631 (Impreso) ISSN 2154-4794 (Electrónico) 
reflexiones, problemáticas que transitan en común; subrayar los debates en los cuales se encuentran o dialogan.

Sin duda, en una primera mirada puede observarse que los ensayos se concentran en algunas "zonas geográficas" privilegiadas, la primera de las cuales es la literatura de América del Sur, en especial la del Cono Sur en la que se incluye la narrativa del Perú. Roberto Bolaño, autor objeto de varias menciones, establece un puente que nos conecta con la narrativa mexicana y en ésta Jordi Soler tiende un lazo hacia España y la compleja producción que en los noventa sigue buscando comprender la tragedia de la guerra civil y la posterior transición. Si bien este volumen se centra en la literatura latinoamericana, nos ha interesado establecer un nexo con la literatura española, no sólo porque ésta se encuentra atravesada por preocupaciones y experiencias similares en torno a la derrota y a la memoria, sino porque además varios escritores latinoamericanos vinculan en sus textos ambas orillas. Asimismo, las miradas sobre las particulares condiciones culturales y políticas de Puerto Rico y Cuba, y sobre la poesía y narrativa centroamericana completan este "recorrido geográfico".

Más allá de este "mapa” de los territorios literarios considerados en la antología, puede establecerse un entramado de categorías ligadas a cuestiones estético-políticas que unen los artículos entre los que podemos rastrear conceptos como utopía/distopía, desencanto, pérdida y derrota, ruina, tedio, derrumbe, apocalipsis, residuo, traición, duelo, melancolía, desarme. Intentamos establecer algunos de los hilos que tejen esta red de relaciones entre ellos, mostrar al vincularlos, más allá de sus particulares enfoques, su pertenencia a un momento de reflexión crítica marcada por las mismas preocupaciones. Así como todos ellos trabajan con textos que de un modo u otro señalan un momento de quiebre, un cierto pasaje estético y político hacia "otra cosa”, los ensayos se hacen cargo de ese cambio e intentan analizarlo y explicarlo. Se trata, en resumen, de "hilvanar el hilo de la red" que los une a través de esos términos que los atraviesan.

Todos los artículos anclan en coyunturas políticas bien precisas de los años noventa, y en muchos casos establecen nexos con episodios históricos y culturales de los sesenta y setenta frente a los cuales la nueva producción literaria parece instaurar sus diferencias. Del mismo modo, puede leerse en muchos de ellos cómo se va configurando el debate en torno a los cambios en el modo de concebir la figura del intelectual luego del “desastre”: la pérdida de la sacralización del artista y la búsqueda de nuevas prácticas y funciones frente al profundo quiebre producido atraviesan las ficciones y la crítica que se ocupa de ellas.

El trabajo de Teresa Basile, “El desarme de Calibán”, abre este recorrido marcando un punto preciso, un punto de inflexión y cambio fundamental entre los años sesenta y noventa al enfocarse en el género ensayo y explorar el "desarme" del intelectual en el escenario de la posdictadura del Cono Sur, trazando una línea que va desde la figura del Calibán revolucionario de los sesenta hasta su desarme en los noventa. Basile considera

Revista Iberoamericana, Vol. LXXX, Núm. 247, Abril-Junio 2014, $327-349$
ISSN 0034-9631 (Impreso) 
el desarme como una de las alternativas que surge luego de la derrota de la izquierda armada y del fin de las dictaduras de los setenta y ochenta, es decir, como una propuesta que se articula en el contexto de la apertura democrática de los noventa. Una pregunta eje del trabajo se refiere al modo en que la experiencia de la derrota dio lugar a nuevos debates en el campo intelectual y literario de la posdictadura uruguaya. Basile analiza cómo el ensayo de Hugo Achugar, escrito en los inicios de la democracia, desarma desde los saberes de la derrota la figura del intelectual revolucionario, cuestiona sus narrativas redentoristas, interpela sus prácticas de discusión y confrontación, y explora la violencia simbólica de la letra en la historia del Uruguay. La "forma” del ensayo propuesta por Achugar traduce estos saberes antitotalitarios de la derrota en el empleo de determinados procedimientos y modos del discurso y de la argumentación. En este espacio, Achugar interpela la escena de la posdictadura y reconvierte esos saberes en escritura.

El desarme es el resultado innegable de una derrota y varios trabajos se ocupan de ella: Ana María Amar Sánchez en “Una narrativa entre la utopía y la derrota. Literatura y política en el fin del milenio” se enfoca en la figura del perdedor y sus connotaciones político-éticas a través de un corpus de textos mexicanos de Paco I. Taibo II, Jorge Volpi, José María Pérez Gay y Jordi Soler. El objetivo es analizar cómo la literatura lo ha representado, qué tipo de estrategias para sobrevivir propone, qué imágenes de la pérdida construye. Se trata de relatos en los que la metáfora del fracaso constituye una lectura y una evaluación de un período histórico. El trabajo desarrolla un análisis de las categorías teóricas con las que se analiza el concepto de “perdedor”, sus diferencias con el fracasado, su relación con las nociones de duelo y melancolía. Tanto la resistencia como el desencanto y la desilusión de las utopías son leídos como posiciones éticopolíticas específicas; en ese sentido, son fundamentales los debates planteados por Alan Badiou, Michel Onfray, Reyes Mate, Roberto Esposito, Jacques Rancière. Todos ellos tienen en común un intento de repensar la política, alejándose de la tradicional mirada que la une indisolublemente al Estado; sus relecturas de la política y de la ética son, en el campo de la teoría, paralelas a los debates que pueden leerse en las representaciones ficcionales analizadas.

A su vez, Miriam Chiani aborda otra inflexión de la derrota en "Lecturas de la derrota y el fracaso en la producción narrativa y crítica de Marcelo Cohen”. Analiza las "representaciones" de la derrota política de la izquierda argentina y señala que estas representaciones sólo constituyen un resto, configuran un "momento" en las historias que articula la narrativa de Marcelo Cohen, sin llegar a convertirse en centro reificado. Chiani desliga el "fracaso” y la “derrota” de los imperativos y los protocolos de la memoria, de géneros como el testimonio y la novela histórica, de las estéticas de lo real maravilloso y del realismo socialista, de las literaturas de denuncia, de la “prosa de estado”, para explorar la matriz del “realismo inseguro" -y sus vínculos con la teoría del caos- que Cohen emplea como estética que se abre a la incertidumbre, a

\footnotetext{
Revista Iberoamericana, Vol. LXXX, Núm. 247, Abril-Junio 2014, 327-349 ISSN 0034-9631 (Impreso) ISSN 2154-4794 (Electrónico)
} 
las disonancias, a la inestabilidad, a las líneas de fuga, a lo imprevisible, a un "nuevo sublime" en el que la certeza del fracaso exige un mayor compromiso con el trabajo de la imaginación. En esta línea, el "realismo inseguro", más que volver al pasado para repararlo en sus injusticias y silencios o hacerlo objeto único y constante de reflexión o representación, desconfía de las totalizaciones restauradoras y prefiere explotar las posibilidades que aún entre despojos, pérdidas, ruinas, escombros o deshechos, ofrece el presente. El análisis considera el temprano relato "El porvenir es más duro que el granito”, junto con El testamento de O'Jaral, Inolvidables veladas y Hombres amables en contrapunto con la producción teórico-crítica de Cohen, en especial sus reflexiones en torno al "realismo inseguro", la "prosa de estado" y la ciencia ficción.

Otro matiz de la derrota que se conecta con el anterior se encuentra en el artículo de Gonzalo Oyola, “Agarrar el caño desinflado en la eyaculada guerra. Notas sobre las crónicas de Pedro Lemebel en los años noventa”, quien explora los comienzos de Pedro Lemebel en la crónica, focalizando en sus dos primeros libros, La esquina es mi corazón y Loco afán. El trabajo visualiza en estos textos una política de la estética a través de la cual el escritor chileno intervino en diversos debates, proponiendo una mirada sobre la historia latinoamericana desde la perspectiva de las minorías de la diversidad sexual, y a contrapelo de las grandes líneas sobre las que se ha construido la historia continental. Según Oyola, las crónicas de Lemebel toman sus materiales de los residuos producidos por los relatos mayores de los vencedores, pero también polemizan con las miradas totalizadoras de la cultura de la izquierda militante. El artículo considera que en la escritura de Lemebel la pérdida y la derrota nombran lo des-hecho por los procesos de dominación, y muestran las dictaduras de los años setenta como un eslabón reciente en la cadena de barbarie dominadora padecida desde la Conquista. La escritura de Lemebel comparte con las figuraciones alegóricas posdictatoriales su interpelación de la historia desde las pérdidas, pero se aleja de ellas en el modo de resolver estas carencias: en él no hay melancolía porque el régimen de su texto es la perversión, compone entonces esperpentos que incorporan materiales marcados por historicidades diversas como huellas de lo que se ha caído de la historia oficial de los vencedores.

La articulación que establecen los trabajos de Chiani y Oyola entre la derrota y una particular estética-que rescataría el resto, el residuo que aquella produce-genera un fuerte entramado en el ensayo de María Lourdes Dávila. Su artículo, "Verlo. Leerlo. Eduardo Lalo frente a la escritura fotográfica latinoamericana”, se enfoca en la obra donde de este autor y en su compleja relación entre fotografía y texto. La fotografía sirve de gozne para un pasaje continuo entre la historia y la literatura; forma parte entonces de un proceso escritural; se piensa como un elemento de un discurso que incluye a un mismo tiempo imagen visual y texto verbal. La obra híbrida de Lalo sería una respuesta particular a la saturación de los discursos producida desde el espacio de "no poder ser posnacional". La visión del triunfo y el fracaso de las ideologías posteriores a la independencia de

\footnotetext{
Revista Iberoamericana, Vol. LXXX, Núm. 247, Abril-Junio 2014, 327-349 ISSN 0034-9631 (Impreso) ISSN 2154-4794 (Electrónico)
} 
las naciones latinoamericanas, la revisión de los discursos ideológicos de Occidente realizados a partir del fin de las dictaduras latinoamericanas desde un espacio-nación, no alcanzan para explicar esa pérdida en Puerto Rico. La saturación de estos discursos se ve reflejada en la literatura de Lalo quien la lleva a su límite produciendo quiebres en el entramado verbal. La noción de grieta surge allí como un signo textual esencial y abundan las alusiones a ella, a los restos, los rastros, los fragmentos y a la función de un escritor y un lector que actúen como arqueólogos. La grieta es la falla que anuncia la destrucción, que interrumpe la historia; la grieta verbal en Lalo observa y hace visible estos mismos discursos desde el espacio de la pérdida, es decir, desde el testimonio del que ha perdido; las fotos narran entonces un presente marcado a un mismo tiempo por los signos de la modernidad y los signos de un proceso de pérdida y ruina.

Las estéticas de la derrota y del desarme, ligadas a las nociones de resto, residuo, grieta, nos remiten a otros trabajos de esta antología estructurados en torno a conceptos pertenecientes a campos semánticos muy cercanos: las diversas inflexiones de la pérdida y sus resultados se despliegan desde el tedio y al aburrimiento hasta la violencia y el cinismo, atravesando la ruina y el derrumbe.

Karina Miller en "La experiencia del vacío: tedio y política en novelas argentinas del 2000” se enfoca en algunas novelas argentinas publicadas recientemente, Bajo este sol tremendo de Carlos Busqued, Opendoor de Iosi Havilio, Las teorías salvajes de Pola Oloixarac, como relatos que elaboran representaciones del tedio, el aburrimiento, la abulia. En ellos se reitera y enfatiza el tiempo improductivo de la espera o de la alienación, el tiempo vacío y la imposibilidad de una idea de progreso. La propuesta del ensayo es indagar en las implicancias ético-políticas de estas representaciones y cómo funcionan con respecto a una concepción de la historia. La desintegración de la cultura del trabajo y de cualquier proyecto político y nacional durante los años noventa son rasgos fundamentales de estas novelas. La pérdida del poder crítico o emancipatorio en la nueva producción literaria argentina tiene que ver con una forma de narrar el presente que se aleja de los discursos canónicos de la literatura, la historia y la cultura. Miller se pregunta si ese deslizamiento del discurso de "literaturidad" no es lo que abre una dimensión ética a la escritura y permite la articulación entre la literatura y lo político desde otra nueva perspectiva que surge a partir de los años noventa, cuando los grandes proyectos de los intelectuales del siglo xix y de los ideales revolucionarios de los setenta desembocaron en una retórica vacía donde el cambio ha perdido su potencial positivo. La experiencia extrema del aburrimiento no propone nada, sólo denuncia la imposibilidad de pensar el presente en términos de un deseo utópico.

Si el tedio y la abulia son parte de la experiencia del fracaso, son algunas de las opciones -opuestas sin duda a la resistencia de otros perdedores- frente a la aceptación de la derrota, los efectos de ésta producen otras “metáforas de la caída” de las esperanzas y de las ilusiones: el naufragio y la ruina, asociadas en Díaz-Infante a la melancolía (que,

\footnotetext{
Revista Iberoamericana, Vol. LXXX, Núm. 247, Abril-Junio 2014, 327-349 ISSN 0034-9631 (Impreso) ISSN 2154-4794 (Electrónico)
} 
a su vez, nos remite a los trabajos de Morales-Rivera y de Paula Aguilar) y el derrumbe en el ensayo de Torre, resultado de la violencia pasada. Violencia que da lugar a una “estética del cinismo” según la perspectiva de Vila.

““Visión sobre los escombros’: Ruina y melancolía en la narrativa cubana del ‘período especial”” de Duanel Díaz-Infante parte del corte que supone el inicio del "período especial” (1989) en la configuración de la narrativa posrevolucionaria cubana, cuyo emblema más destacado es la "ruina”. Desde ese umbral, explora la “dialéctica” entre la revolución y la ruina, entendiendo el concepto de “dialéctica” no como una síntesis dinámica entre contrarios (Hegel), sino como la conversión de un ideal en su opuesto (Adorno y Horkheimer) que se lleva a cabo en el paso de la década de los sesenta a la de los noventa: de la "revolución” a la "ruina”, de la "aceleración de la historia” a su detención, del "Evento” a la stasis (Zizek), de la "utopía” a la “nostalgia” (Sontag). El corpus textual seleccionado ilustra, entonces, estos dos momentos: las ruinas en la narrativa de la revolución -en los relatos "Estatuas sepultadas” (1967) de Benítez Rojo y en “Casa sitiada” (1969) de César Leante- remiten a la burguesía cuyas casas son simbólicamente "tomadas" por las masas revolucionarias o aisladas del mundo exterior sacudido por el proceso revolucionario que constituye el Evento y la utopía; mientras "Visión sobre los escombros" (1998) de Pedro Juan Gutiérrez y "Un arte de hacer ruinas” (1998) de Antonio José Ponte exhiben los nuevos significados que las ruinas adquieren en la narrativa posrevolucionaria como figuras del "naufragio de la utopía de los sesenta”, de la stasis, y asimismo de la emergencia de una nostalgia por la Cuba prerrevolucionaria.

El trabajo de María Elena Torre, "Entre la fundación y el derrumbre: La violencia del tiempo de Miguel Gutiérrez” recorre un preciso itinerario que va desde la temprana pertenencia del autor peruano, en la década de los sesenta, al grupo Narración integrado por escritores de izquierda comprometidos con las causas de los sectores marginados, en cuyo programa hay una fuerte apuesta al vínculo entre literatura y política, una inclinación hacia el realismo socialista y el realismo crítico sin descartar algunos aportes vanguardistas, y una filiación con la estirpe de Amauta de José Carlos Mariátegui, hasta la década de los noventa atravesada por la derrota de Sendero Luminoso (cuyo ideario fue apoyado en gran parte por Miguel Gutiérrez) que lo conduce a revisar tanto sus ideas políticas como su propuesta literaria. Se trata entonces, de un recorrido pautado entre la "fundación” y el “derrumbe” como asegura el título que hace de la "derrota” (emblematizada en la captura del líder Abimael Guzmán en 1992) un dispositivo desde el cual se lee tanto un cambio en las posturas políticas como en los diseños estéticos por parte de Miguel Gutiérrez. Torre ubica, además, la novela de Gutiérrez en una serie literaria integrada por Alonso Cueto, Santiago Roncagliolo y Oswaldo Reynoso, entre otros, con los que comparte el interés por explorar “el tiempo del miedo” como se denominó a la época senderista.

\footnotetext{
Revista Iberoamericana, Vol. LXXX, Núm. 247, Abril-Junio 2014, 327-349 ISSN 0034-9631 (Impreso) ISSN 2154-4794 (Electrónico)
} 
En "Las ilusiones perdidas: narrar la violencia. Acercamientos a la obra de Horacio Castellanos Moya”, María del Pilar Vila sitúa en la década de los noventa, con la derrota electoral de los sandinistas como fecha emblemática, la emergencia -un mini-boomde una narrativa de la violencia, producto del desencanto, de la pérdida de liderazgo y de la pérdida de fe en los proyectos utópicos que formaban parte del momento revolucionario en Nicaragua, El Salvador y Guatemala. Esta "narrativa de posguerra”, “de violencia” o "estética del cinismo", tal como la crítica ha intentado definirla en un sostenido debate, cuenta en sus filas a Sergio Ramírez (Nicaragua), Carlos Cortés (Costa Rica), Franz Galich (Guatemala-Nicaragua), Rodrigo Rey Rosa (Guatemala), entre otros escritores. Una de las claves que recorre el análisis de Pilar Vila sostiene que la pérdida de la esperanza puesta en los proyectos políticos revolucionarios y en los relatos utópicos fue sustituida por una violencia sin ideología. En este contexto, Pilar Vila analiza la obra del escritor honduro-salvadoreño Horacio Castellanos Moya, deteniéndose en El asco. Thomas Bernhard en San Salvador, El arma en el hombre, Tirana memoria, Insensatez, Baile con serpientes y en los cuentos de Con la congoja de la pasada tormenta, para señalar en esta narrativa la desazón ante el fracaso de los proyectos revolucionarios, la exposición de la decadencia, la violencia sin ideología y el vaciamiento de la idea de Nación.

Es posible pensar que un punto culminante, un resultado absoluto del sentimiento de derrota, ruina y derrumbre, la ausencia de todo futuro y de toda posible utopía, lo constituye el relato apocalíptico. En "2666, o la legitimidad de la literatura en tiempos 'post'”, Ilse Logie analiza la novela de Roberto Bolaño como emblemática de la tradición narrativa posapocalíptica, donde se pone de manifiesto el agotamiento del poder, el final de una época que no conoce zonas no contaminadas por la violencia. De allí que la representación más adecuada del mundo contemporáneo aparezca como una pesadilla caracterizada por esa violencia y por la guerra permanente, verdaderas sinécdoques de la historia contemporánea. 2666 clausura el siglo xx expresando dos naufragios: el primero atañe a la militancia de la izquierda, en la que todavía creía la generación del propio Bolaño, representada por un personaje, Amalfitano, que encarna las derrotas y pérdidas del proyecto revolucionario. El segundo naufragio es el que ha afectado a una concepción humanista del arte; en la actualidad, se asume que la literatura ya raramente incomoda o ilumina. Atrás ha quedado la sacralización de la figura del artista que marcó el período modernista de nuestra cultura, por lo que el arte ha perdido su poder emancipador, ha dejado de ser una fuerza civilizadora para ponerse al servicio de regímenes totalitarios, o para disolverse en el triunfo banal de la industria cultural. El texto parece proponer que para recuperar cierta legitimidad, en una obra debe coincidir el compromiso estético con el ético, por lo que los procesos de ficcionalización no pueden entenderse como meros proyectos estéticos.

Annelies Oeyen en "Hacia una (est)ética del posapocalipsis en la narrativa argentina posdictatorial” rastrea cómo se manifiesta el “posapocalipsis” en un corpus de ficciones

\footnotetext{
Revista Iberoamericana, Vol. LXXX, Núm. 247, Abril-Junio 2014, 327-349 ISSN 0034-9631 (Impreso) ISSN 2154-4794 (Electrónico)
} 
surgidas en la Argentina posdictatorial: Insomnio de Marcelo Cohen, El Aire de Sergio Chejfec y Plop de Rafael Pinedo. Las tres novelas proponen representaciones del mundo tras una catástrofe de gran magnitud; transcurren en un futuro en el que prácticamente no existe la posibilidad de hacer renacer la cultura anterior. El derrumbe se despliega en el desarrollo temporal: se manifiesta en un presente continuo en el que se ha suspendido la cronología clásica y se superponen pasado, presente y futuro. Después de la ruina de la sociedad quedan solamente elementos mínimos, residuos que cuestionan concepciones modernas de la civilización, el progreso y la creencia en la revolución. Varias reescrituras de la figura del "desierto" alimentan esta representación posapocalíptica del espacio. El desierto irrumpe en el seno de las ciudades, que simultáneamente se deshacen de sus connotaciones utópicas de libertad y de evasión. Cada novela parece plantear la pregunta de cómo construir una vida entre las ruinas. La estética del posapocalipsis establece una relación innegable con las inquietudes actuales y muestra los síntomas de la crisis del presente. La realidad extratextual queda extrañada, radicalizada, despojada, barbarizada, lo que desemboca en una literatura marcada por el desencanto, el olvido y el fracaso.

La desilusión ante los proyectos perdidos, es también origen de una narrativa en que las diversas inflexiones del duelo y la melancolía funcionan como hilos conductores. Paula Aguilar analiza una novela temprana de Bolaño (en una lectura diversa y complementaria de la realizada por Logie con 2666) en "Monsieur Pain, o los comienzos de un escritor melancólico" enfocándose en el problema de la "melancolía” como uno de los signos del "terreno afectivo" de la posdictadura chilena. En esta línea propone el estudio de la memoria desde el concepto de anamnesis para abordar los espacios y las escenas donde la memoria trabaja en el interior de Monsieur Pain; recorre las figuras del escritor "melancólico" e "hiperestésico" entre los cuales se encuentra el poeta César Vallejo; desmenuza las complejas tensiones que sacuden a la palabra en su capacidad e incapacidad para hablar del horror, y bucea en una escritura -la de Bolaño- que articula una fuerte voluntad testimonial anclada en las experiencias de la barbarie con las pulsiones del fantástico creado por las pesadillas de esas mismas experiencias. Desde ciertas reconceptualizaciones de la "melancolía” (Butler, Avelar, Gundermann, entre otros) que destacan su capacidad política, Aguilar coloca a Bolaño lejos tanto de la nostalgia de un pasado con sueños de utopía como de una épica de la resistencia heroica para acercarlo a las políticas del presente.

La melancolía adquiere rasgos distintos en el ensayo de Santiago Morales-Rivera "Desencantos ejemplares: estética y afectividad en la España de los años noventa”. El autor analiza qué ha sucedido entre los sesentas y los noventas para que Occidente, en general, y España, en particular, experimenten una "situación profundamente desencantada”. La transformación a partir de los noventa del espíritu utópico de los sesentas se observa de manera especial en uno de los debates más controvertidos en el campo de los estudios hispánicos: el debate en torno al desencanto. El trabajo examina

\footnotetext{
Revista Iberoamericana, Vol. LXXX, Núm. 247, Abril-Junio 2014, 327-349 ISSN 0034-9631 (Impreso) ISSN 2154-4794 (Electrónico)
} 
los vínculos y tensiones entre este desencanto o este desconcierto paradigmáticamente finisecular y cierto humorismo que se expresa en distintos textos literarios. Finalmente, considera las lecciones (sentimentales, políticas, estéticas) que pueden extraerse de semejante forma cínica de interpelar el desconcierto de cara al presente siglo xxi. El artículo se enfoca en Demasiadas preguntas de Félix de Azúa, una novela de 1994 sobre el relevo de poderes durante la transición, y en Hijos sin hijos (1993) de Enrique Vila-Matas, otro narrador de la generación que llega al fin de siglo “desencantada” y "perdida”. El trabajo se incluye en el gran debate crítico y teórico que se abre sobre la narrativa española-y latinoamericana-en las últimas décadas a propósito de los cambios políticos, el ajuste de cuentas con el período dictatorial y la transición a la democracia.

Por último, dos artículos dedicados a la producción poética de figuras como Gelman, Zurita y Cardenal se enfocan en los desplazamientos formales que los cambios de coyunturas históricas generaron en los discursos poéticos. Podría pensarse que es aquí, en el discurso poético, donde mejor puede leerse el modo en que la estética se articula -y acompaña- las mutaciones políticas. El ensayo de Geneviève Fabry, “Trayectorias de la pérdida: una lectura al sesgo de las obras de Raúl Zurita y Juan Gelman” parte del análisis de los conceptos de melancolía y duelo -y en este sentido dialoga con los trabajos de Morales-Rivera y Aguilar- tal como han sido considerados por la crítica en los últimos años y analiza la pertenencia de estas nociones en un corpus poético que incluye los proyectos estéticos del argentino Juan Gelman y el chileno Raúl Zurita. La evolución que sufren sus respectivas obras poéticas durante y después de los procesos dictatoriales de sus países ofrecen puntos de convergencia interesantes. En ambos casos, su trayectoria vital y poética manifiesta el impacto sufrido a raíz de la violencia estatal y social característica de los años setenta; en el lenguaje poético, este impacto se traduce mediante una alegorización del país y del dolor (del país como dolor) que se apoya en intertextos recurrentes, Dante y los profetas bíblicos para Zurita (Purgatorio y Anteparaíso), los místicos castellanos para Gelman(Si dulcemente y Citas y comentarios). Fabry se pregunta cómo se prolonga en la década de los noventa la trayectoria de ambos poetas y cómo se reconfigura el binomio derrota-resistencia en el nuevo contexto político y cultural. El artículo contesta estas preguntas a través de un análisis contrastado de Incompletamente de Gelman y La vida nueva de Zurita, a la luz del ensayo de Slavoj Zizek El frágil absoluto que analiza los proyectos revolucionarios a la luz del presente y del llamado fin de las utopías.

María del Pilar Ríos en “Ernesto Cardenal: los vaivenes de una revolución” recorre hitos fundamentales en la obra del poeta nicaragüense Ernesto Cardenal para estudiar los complejos vínculos entre literatura y política, entre literatura y revolución que se articulan en torno a la experiencia de la Revolución Sandinista. El desplazamiento de la “poesía” a las “memorias” constituye un punto de inflexión en la mirada sobre la revolución de Cardenal, que Pilar Ríos explora: si la poesía va configurando desde

\footnotetext{
Revista Iberoamericana, Vol. LXXX, Núm. 247, Abril-Junio 2014, 327-349 ISSN 0034-9631 (Impreso) ISSN 2154-4794 (Electrónico)
} 
el "exteriorismo" una poética capaz de vehiculizar los saberes e ideologemas de la revolución en su interés por “el mundo exterior”, por la historia de Nicaragua, por los “condenados de la tierra”, por la luchas libertarias, por los “indios americanos”, por la heroicidad de Sandino; en cambio las memorias se vuelven un escenario para argumentar sobre los alcances y logros de la experiencia histórica de la revolución, para revisar sus errores, para señalar las “traiciones”, para anotar las “pérdidas”, desde una mirada que aún apuesta a sus posibilidades futuras.

Las articulaciones establecidas entre los ensayos podrían continuarse: sin duda, la red de vínculos que se entretejen va en múltiples direcciones. De esta manera, toda una constelación de estrategias, textos, categorías que proponen estos trabajos parece configurar un horizonte para leer una buena parte de la narrativa de los años noventa; narrativa en la que la crítica ha podido encontrar una inquietante evaluación política y cultural de los años de derrota y en la que se deslizan también reflexiones -como en los trabajos de Logie, Dávila, Miller, Basile-sobre la función del artista y el intelectual, su pérdida de liderazgo, la ausencia de función de su práctica; la necesidad, finalmente, de repensar el sentido de un presente caracterizado por la pérdida de sentido, de ilusiones y de utopías.

\section{BiBLIOGRAFÍA}

Amar Sánchez, Ana María. Instrucciones para la derrota. Narrativas éticas y políticas de perdedores. Barcelona: Anthropos, 2010.

Avelar, Idelber. Alegorías de la derrota: la ficción posdictatorial y el trabajo del duelo. Santiago de Chile: Cuarto Propio, 2000.

Basile, Teresa. “El desarme de Calibán en el deshielo tropical” (en prensa, 2012).

Beverley, John. Against Literature. Minneapolis: U of Minnesota P, 1993.

Castañeda, Jorge. La utopía desarmada. El futuro de la izquierda en América Latina. Buenos Aires: Ariel, 1993.

Ette, Ottmar y otros. Poéticas del fracaso. Yvette Sánchez y Roland Spiller, eds. Tubinga: Gunter Narr Verlag, 2009.

Fabry, Geneviève, Ilse Logie y Pablo Decock, eds. Los imaginarios apocalípticos en la literatura hispanoamericana contemporánea. Berna: Peter Lang, 2010

Fernández Retamar, Roberto. Calibán. Apuntes sobre la cultura de nuestra América. Buenos Aires: La Pléyade, 1984.

Todo Calibán. San Juan: Callejón, 2003.

Freud, Sigmund. "Duelo y melancolía”. Obras Completas. Tomo XIV. Buenos Aires: Amorrortu, 1976.

Fornet, Jorge. Los nuevos paradigmas. La Habana: Letras cubanas, 2006.

Gundermann, Christian. Actos melancólicos. Formas de resistencia en la posdictadura argentina. Rosario: Beatriz Viterbo, 2007.

\footnotetext{
Revista Iberoamericana, Vol. LXXX, Núm. 247, Abril-Junio 2014, 327-349 ISSN 0034-9631 (Impreso) ISSN 2154-4794 (Electrónico)
} 
Laddaga, Reinaldo. Estética de la emergencia. Buenos Aires: Adriana Hidalgo, 2010.

Petras, James. Neoliberalismo en América Latina: la izquierda devuelve el golpe. Rosario: Homo Sapiens, 1997.

Reati, Fernando. Postales del porvenir. La literatura de anticipación en la Argentina neoliberal (1985-1999). Buenos Aires: Biblos, 2006.

Spiller, Roalnd. "Roberto Bolaño: fracasar con éxito o navigare necessum est”. Poéticas del fracaso. Yvette Sánchez y Roland Spiller, eds. Tubinga: Gunter Narr Verlag, 2009. 143-174.

Wickham-Crowley, Timothy. Guerrillas and Revolution in Latin America: AComparative Study of Insurgents and Regimes since 1956. Princeton: Princeton UP, 1992.

Vezzetti, Hugo. “Derechos humanos y psicoanálisis”. Punto de Vista 28 (1986): 5-8. Pasado y presente. Guerra, dictadura y sociedad en la Argentina. Buenos Aires: Siglo XXI, 2002.

“Variaciones sobre la memoria social”. Revista de Crítica Cultural 17 (1998): 8-13.

Revista Iberoamericana, Vol. LXXX, Núm. 247, Abril-Junio 2014,
ISSN 0034-9631 (Impreso) 
